\title{
Influence of a $\mathrm{Cu}$-zirconia interface structure on $\mathrm{CO}_{2}$ adsorption and activation
}

Lars Gell, Aku Lempelto, Toni Kiljunen, and Karoliina Honkala ${ }^{a}$

Department of Chemistry, Nanoscience Center, P.O. Box 35 (YN) FI-40014, University of Jyväskylä, Finland

(Dated: 3 March 2021)

$\mathrm{CO}_{2}$ adsorption and activation on a catalyst is a key elementary step for $\mathrm{CO}_{2}$ conversion to various valuable products. In the present computational study, we screened different $\mathrm{Cu}-\mathrm{ZrO}_{2}$ interface structures and analysed the influence of the interface structure on $\mathrm{CO}_{2}$ binding strength using density functional theory calculations. Our results demonstrate that a $\mathrm{Cu}$ nanorod favours one position on both tetragonal and monoclinic $\mathrm{ZrO}_{2}$ surfaces, where the bottom $\mathrm{Cu}$ atoms are placed close the lattice oxygens. $\mathrm{CO}_{2}$ prefers a bent bidentate configuration at the interface and the molecule is clearly activated being negatively charged. Straining of the $\mathrm{Cu}$ nanorod influences $\mathrm{CO}_{2}$ adsorption energy but does not change the preferred nanorod position on zirconia. Altogether, our results highlight that $\mathrm{CO}_{2}$ adsorption and activation depend sensitively on the chemical composition and atomic structure of the interface used in the calculations. This structure sensitivity may potentially impact further catalytic steps and the overall computed reactivity profile.

Keywords: heterogeneous catalysis, density functional theory, $\mathrm{CO}_{2}$ activation, metaloxide interface

\footnotetext{
a) karoliina.honkala@jyu.fi
} 


\section{INTRODUCTION}

Chemical transformations of $\mathrm{CO}_{2}$ into fuels and platform chemicals have been identified as a highly promising approach to alleviate anthropogenic $\mathrm{CO}_{2}$ providing a wastevalue approach to upgrade $\mathrm{CO}_{2}$ into building block and value-added products for chemical industry. ${ }^{1-3}$ Due to the highly oxidized state, thermodynamic stability, and unreactive nature of $\mathrm{CO}_{2}$, economical, active, and selective catalysts are mandatory and the chemical conversion and the economical utilization of $\mathrm{CO}_{2}$ is a notable scientific and technical challenge. ${ }^{1}$

Numerous experimental and computational studies have shown that $\mathrm{CO}_{2}$ reduction takes place at a metal-oxide interface, ${ }^{4-10}$ which is also an active domain for many other industrially important catalytic reactions ${ }^{11}$ such as the water-gas-shift reaction ${ }^{12,13}$ and CO oxidation $^{14,15}$ just to mention but a few. These reactions have been reported to take place over a variety of metal-oxide interfaces with diverse chemical nature and composition e.g., $\mathrm{Au}-\mathrm{TiO}_{2},{ }^{15-17} \mathrm{Cu}-\mathrm{ZnO},{ }^{4,9} \mathrm{Rh}-\mathrm{ZrO}_{2},{ }^{13,18} \mathrm{FeO}-\mathrm{Pt},{ }^{19} \mathrm{Pd}-\mathrm{Co}_{3} \mathrm{O}_{4},{ }^{20,21} \mathrm{Pt}-\mathrm{SiO}_{2}{ }^{22,23}$, and others ${ }^{24}$. As the experimental characterization of interface structures at the atomic level is demanding, density functional theory (DFT) modelling is extensively used to obtain microscopic information about chemical and structural properties of interfaces ${ }^{4,13,15,17,25,26}$ and to establish structure-performance relationships ${ }^{25}$. While the catalyst models used in DFT calculations must be firmly based on real catalytic systems, simplifications are mandatory to reduce the computational burden. The key feature of a catalyst to be captured by the model is an active site. Typically, the employed models vary depending on the chemical composition and nature of the active site. For metal-only active sites, periodic surface slab models are commonly used, ${ }^{27-30}$ whereas active sites consisting of a metal-oxide interface are often represented by oxide-supported metal clusters ${ }^{8,31-34}$ or infinitely long nanorods ${ }^{13,15,25,26}$.

Among the possible chemical transformations, $\mathrm{CO}_{2}$ conversion to methanol is particularly interesting due to the potential of methanol as a future energy carrier. ${ }^{2,35}$ While $\mathrm{Cu} / \mathrm{ZnO} / \mathrm{Al}_{2} \mathrm{O}_{3}$ catalysts are commonly used in industry to produce methanol from $\mathrm{CO}$

and they have also been successfully applied to $\mathrm{CO}_{2}$ reduction to methanol, ${ }^{2,5,36,37} \mathrm{ZrO}_{2}$ supported or promoted $\mathrm{Cu}$ catalysts have been identified as promising alternatives due to their higher selectivities and turn over frequencies towards methanol. ${ }^{5,6,38-40}$ Recent studies indicate that a reaction mechanism and selectivity are determined by adsorption energies of key reaction intermediates..$^{5,8,26,31}$ Two central reaction steps, namely $\mathrm{H}_{2}$ dissociation ${ }^{41,42}$ 
and $\mathrm{CO}_{2}$ activation, are strongly associated to the $\mathrm{Cu}-\mathrm{ZrO}_{2}$ interface. ${ }^{5,38,43}$ The reaction is inferred to be structure sensitive on $\mathrm{Cu}$ and the synergy between $\mathrm{Cu}$ and support oxides is responsible for enhanced reactivity ${ }^{4,5,44-48}$. In calculations, however, adsorption characteristics may sensitively depend on a constructed catalyst model, and small differences between relatively similar active sites may introduce large variations in adsorption energies as shown, e.g., for $\mathrm{CO}$ adsorption zirconia supported metal clusters. ${ }^{33}$ Computationally $\mathrm{CO}_{2}$ conversion to methanol has been recently studied employing a $\mathrm{Cu}_{38}$ cluster model supported on a $m-\mathrm{ZrO}_{2}(\overline{1} 11)$ surface $^{8}$ and a $\mathrm{Cu}$ nanorod model, which is composed of three layers of stacked $\mathrm{Cu}(100)$ facets on $t-\mathrm{ZrO}_{2}(101)^{26}$. A similar nanorod model was also used for a Au-MgO interface to address a water-gas-shift reaction. ${ }^{12}$ In another computational study, the catalytic properties of various metal- $\mathrm{MgO}$ interfaces were considered using rods that also consist of (100) terminated slices but cut in a different orientation to better match the symmetry of $\mathrm{MgO}(100) .{ }^{25} \mathrm{CO}_{2}$ reduction on $\mathrm{SiO}_{2}$ and $\mathrm{TiO}_{2}$ supported $\mathrm{Pt}$ was, in turn, investigated using a $\mathrm{Pt}_{25}$ cluster, also composed of stacked (100) facets and exposing (111) microfacets towards the interface. ${ }^{31}$ A differently shaped Rh nanorod, terminated by (111) facets on each side was employed for a water-gas-shift reaction on $\mathrm{ZrO}_{2}{ }^{13}$ and a similar model was used for Au$\mathrm{TiO}_{2}$ to address $\mathrm{CO}$ oxidation ${ }^{15}$ as well as low temperature $\mathrm{H}_{2}$ oxidation ${ }^{49}$. As one would expect, the symmetry and periodicity of the underlying support oxide naturally influences the interface and must therefore be considered. For highly symmetric oxide surfaces, such as $\mathrm{MgO}(100)$, the orientation of a deposited nanorod has a vanishingly small impact on the interface. For less symmetric oxides, the position and orientation of the nanorod can substantially change the interface structure. For example, a monoclinic $\mathrm{ZrO}_{2}(\overline{1} 11)$ surface displays a less symmetric crystal structure than a tetragonal $\mathrm{ZrO}_{2}(101)$ surface. One more feature that may affect interface reactivity is strain effects ${ }^{25}$, which together with defects in catalytic metal particles have been suggested to significantly impact on catalytic efficiency. ${ }^{25,50,51}$ This is hardly surprising as it is well established from the numerous studies that straining of metal surfaces changes their reactivity observed as shifts in d-band centers. ${ }^{30,52}$ Artificial strain effects may emerge in the construction of atomic models for metal - oxide interfaces, because the lattice mismatch between metal and oxide will introduce strain along the nanorod as it has to meet the periodicity set for the support surface.

In this study, we focus on $\mathrm{CO}_{2}$ adsorption and activation on various $\mathrm{Cu}-\mathrm{ZrO}_{2}$ interface structures to shed light on the influence of the interface properties on $\mathrm{CO}_{2}$ binding. 
Specifically, we considered two $\mathrm{Cu}$ nanorod models with different geometries as well as both tetragonal $\left(t-\mathrm{ZrO}_{2}(101)\right)$ and monoclinic $\left(m-\mathrm{ZrO}_{2}(\overline{1} 11)\right)$ zirconia surfaces. A comprehensive screening of nanorod positions was performed on the oxide and $\mathrm{CO}_{2}$ characteristics were analysed for differently strained interfaces. The adsorption process was broken down to distinct electronic contributions, and they were used to attempt to establish general trends between interface structure and its ability to adsorb and activate $\mathrm{CO}_{2}$.

\section{COMPUTATIONAL METHODS}

All density functional theory (DFT) calculations were carried out using the BEEF-vdW exchange-correlation functional ${ }^{53}$ in the projector-augmented wave $(\mathrm{PAW})^{54}$ formalism as implemented in the GPAW ${ }^{55}$ package. The core electrons of all elements were described by PAW setups in the frozen-core approximation. A maximum spacing of $0.18 \AA$ was used for the real-space grid basis, and the reciprocal space was sampled at the $\Gamma$ point. Periodic boundary conditions were used in two directions. A Hubbard U correction ${ }^{56}$ of $2.0 \mathrm{eV}$ was applied to the d-orbitals of the zirconium atoms. The geometry optimizations were performed using the BFGS algorithm as implemented in the Atomic Simulation Environment (ASE). ${ }^{57}$ The computed electronic structures were analyzed by the Bader partitioning method $^{58}$ using code written by Tang et al. ${ }^{59}$ to obtain the distribution of partial charges on individual atoms. The density of states was analyzed to locate the d-band centers for the purpose of investigating their importance to the reactivity of the $\mathrm{Cu}$ nanorods according to the d-band model. ${ }^{60}$

The interface models were built by placing a $\mathrm{Cu}$ nanorod over the most stable facets of monoclinic and tetragonal zirconia surfaces, $m-\mathrm{ZrO}_{2}(\overline{111})$ and $t-\mathrm{ZrO}_{2}(101)$, as supports (see Fig. 1 for an overview). We adopted two $\mathrm{Cu}$ nanorod models, similar to those that have been used in previous publications, ${ }^{13,25,26}$ to be used in the present study. Both models have an equal number of atoms, and they display a (111) facet towards the reactive Cu-zirconia interface. The nanorod structures differ by the facet via which they are attached to the zirconia support. The bottom interface is either a (100) facet or a (111) facet; hence we will call them here the (100) and (111) models, respectively. As Figs. 1 and S1 show, the (100) model has a more gently sloping reactive interface than the (111) model. Under the reaction conditions of $\mathrm{CO}_{2}$ conversion to methanol, the most common exposed $\mathrm{Cu}$ surfaces 


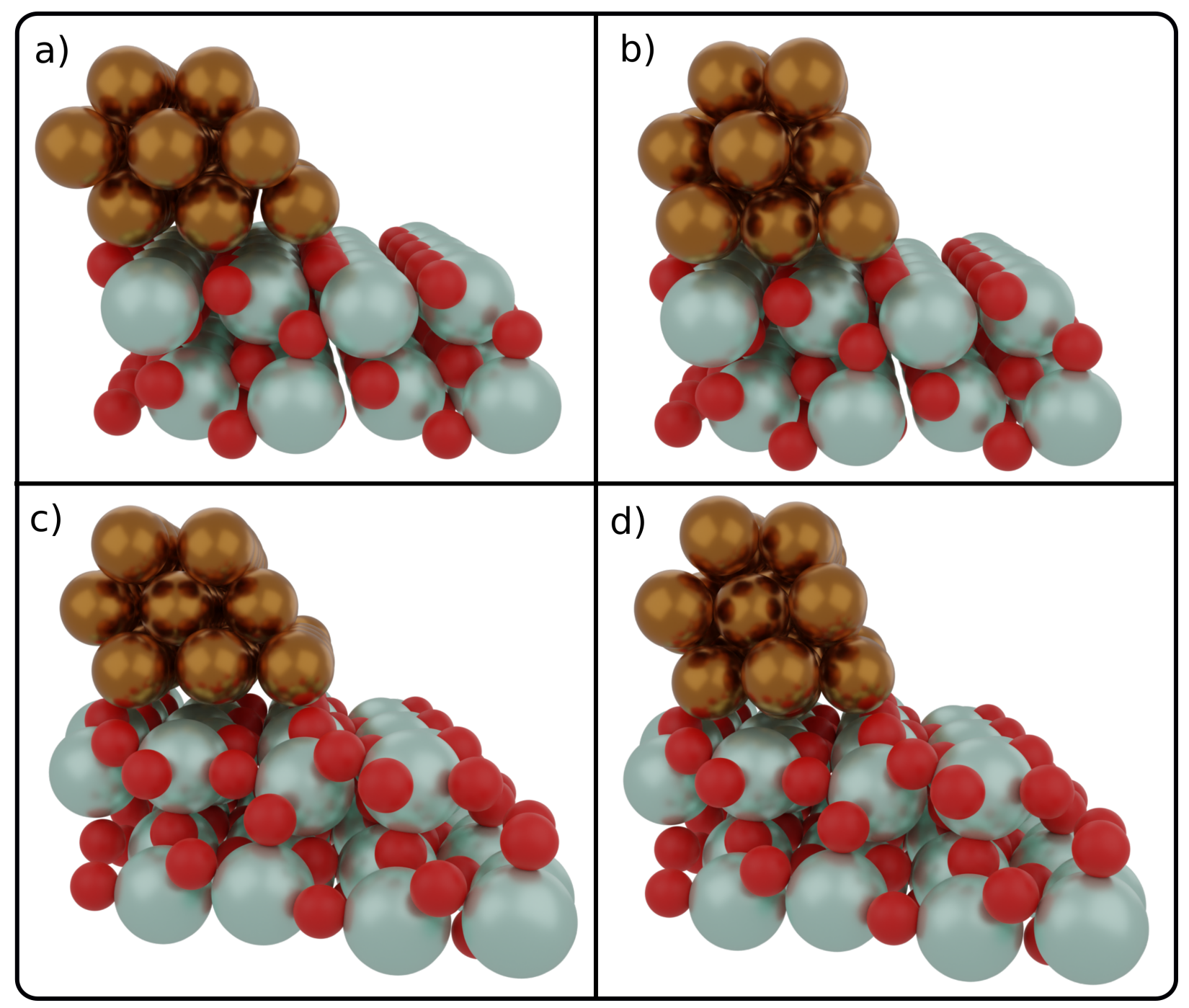

FIG. 1. The optimized minimum energy structures of a $\mathrm{Cu}$ nanorod on tetragonal or monoclinic zirconia supports. a) (100) $/ t-\mathrm{ZrO}_{2}$, b) (111) $/ t-\mathrm{ZrO}_{2}$, c) $(100) / m-\mathrm{ZrO}_{2}$, d) (111) $/ m-\mathrm{ZrO}_{2}$.

are (111) and (100) of which (111) is slightly more stable. ${ }^{61}$

\section{A. Model system screening}

Figure 1 illustrates the catalytic model systems for both nanorod models and supports. Screening of the rod position was carried out by displacing the nanorods in two directions on the support: along and perpendicular to the nanorod, while keeping the orientation fixed. To scan the surface, we used a grid of $0.7 \AA$ steps along the nanorod axis, and $1.1 \AA$ or $1.5 \AA$ steps perpendicular to the nanorod for the $t-\mathrm{ZrO}_{2}$ or $m-\mathrm{ZrO}_{2}$, respectively. The $\mathrm{CO}_{2}$ 
binding was studied by attaching the molecule to one of the bottom-row $\mathrm{Cu}$ atoms at the reactive interface.

The oxide support was described by a slab model, the thickness of which was set to two stoichiometric layers. This approximation is necessary to reduce the computational burden especially in the larger cells (see below). We consider the two-layer model sufficient to reveal general trends when comparing the nanorod models, and justified, since in preliminary evaluations with two to four layers, the $\mathrm{Cu}$-zirconia binding energy showed only minor variation. We also determined that the d-band centers of the interfacial copper atoms varied insignificantly between different slab thicknesses. However, the $\mathrm{CO}_{2}$ adsorption energy depends on slab thickness and Test calculations showed that a thicker slab would enhance the binding. In geometry optimizations, the bottom layer of the zirconia slab was kept frozen to its initial bulk geometry, while the top zirconia layer, the $\mathrm{Cu}$ nanorod, and the possible $\mathrm{CO}_{2}$ adsorbate were allowed to relax until the maximum residual force was reduced below $0.02 \mathrm{eV} \AA^{-1}$.

\section{B. Strain of the nanorod}

With the present DFT model, we obtain a bulk Cu lattice constant of $3.69 \AA$ which leads to $2.61 \AA$ nearest-neighbor $\mathrm{Cu}-\mathrm{Cu}$ distance prior to modifications. The nanorods were created by repeating periodic $\mathrm{Cu}_{8}$ minimum nanorod units having length of one atom. Our computationally determined zirconia lattice constants can be found from Table S1. To explore possible implications of the artificial strain on the metal-oxide interface, we studied five different nanorod lengths on tetragonal $\mathrm{ZrO}_{2}$ and three on monoclinic $\mathrm{ZrO}_{2}$ surfaces, see Table S2 for numerical details of the cell sizes.

Because the calculations have to be periodic along the length of the rod, the $\mathrm{Cu}-\mathrm{Cu}$ distance modified in that direction was always adjusted accordingly to meet the periodicity of the given surface unit cell. We define the strain as positive when the nanorod is stretched and negative when it is compressed relative to the computationally optimized bulk $\mathrm{Cu}$ lattice constant. The nanorods illustrated in Fig. 1 are those with the lowest strains, with $t-\mathrm{ZrO}_{2}$ support producing a $-0.72 \%$ and $m-\mathrm{ZrO}_{2}$ a $-1.02 \%$ strain. Overall, the strain varies from -7.3 to $+8.1 \%$ between the different surface models investigated. 


\section{Energy decomposition}

The energy decomposition was set to characterize different contributions in the adsorption of $\mathrm{CO}_{2}$ at the catalytic sites. First, the adsorption energy of $\mathrm{CO}_{2}$ was computed from the total energies as

$$
\Delta E_{\mathrm{ads}}=E_{\mathrm{CO}_{2} / \mathrm{Cu} / \mathrm{ZrO}_{2}}-E_{\mathrm{Cu} / \mathrm{ZrO}_{2}}-E_{\mathrm{CO}_{2}}
$$

where $E_{\mathrm{CO}_{2} / \mathrm{Cu} / \mathrm{ZrO}_{2}}$ stands for the full system, $E_{\mathrm{Cu} / \mathrm{ZrO}_{2}}$ for the bare $\mathrm{ZrO}_{2}$-supported $\mathrm{Cu}$ nanorod, and $E_{\mathrm{CO}_{2}}$ for the gas-phase (linear, inactivated) $\mathrm{CO}_{2}$. The gas-phase reference was computed in a large non-periodic cell. We will use the adsorption energy difference $\Delta \Delta E_{\text {ads }}$ to compare the different interface model systems. Then, to exclude the contribution of atomic relaxations from the above $\mathrm{CO}_{2}-\mathrm{Cu} / \mathrm{ZrO}_{2}$ bond strength, we computed the total electronic interaction energy as

$$
\Delta E_{\mathrm{el}}^{\mathrm{tot}}=E_{\mathrm{CO}_{2} / \mathrm{Cu} / \mathrm{ZrO}_{2}}-E_{\mathrm{Cu} / \mathrm{ZrO}_{2}}^{*}-E_{\mathrm{CO}_{2}}^{*}
$$

Here, asterisks stand for reference configurations, where all the atomic positions were fixed to those optimized for the full system. The adsorption and electronic interaction energies in Eqs. (1) and (2) thus differ by an energy penalty required by the deformation of the catalyst and the $\mathrm{CO}_{2}$ molecule upon adsorption. Again, for comparison, we define $\Delta \Delta E_{\mathrm{el}}^{\text {tot }}$ to assess the difference between the models.

The electronic interaction energies between the $\mathrm{CO}_{2}$ molecule and the catalyst components $\mathrm{Cu}$ and $\mathrm{ZrO}_{2}$ were separated according to

$$
\begin{gathered}
\Delta E_{\mathrm{el}}^{\mathrm{Cu}}=E_{\mathrm{CO}_{2} / \mathrm{Cu}}^{*}-E_{\mathrm{Cu}}^{*}-E_{\mathrm{CO}_{2}}^{*}, \\
\Delta E_{\mathrm{el}}^{\mathrm{Zr}}=E_{\mathrm{CO}_{2} / \mathrm{ZrO}_{2}}^{*}-E_{\mathrm{ZrO}_{2}}^{*}-E_{\mathrm{CO}_{2}}^{*} .
\end{gathered}
$$

Again, the atomic coordinates of the $\mathrm{CO}_{2}$ and the isolated $\mathrm{Cu}$ nanorod and $\mathrm{ZrO}_{2}$ were fixed to those optimized for the full system. Summing Eqs. (3) and (4) together accounts for the pairwise contributions to the three-body interaction in Eq. (2). Finally, to account for the missing contribution to the total electronic interaction, we define an excess energy

$$
\Delta E_{\mathrm{exc}}=\Delta E_{\mathrm{el}}^{\mathrm{tot}}-\Delta E_{\mathrm{el}}^{\mathrm{Cu}}-\Delta E_{\mathrm{el}}^{\mathrm{Zr}}
$$

which describes the change in electronic interaction energy due to the synergy effect of the metal-oxide interface. 


\section{RESULTS AND DISCUSSION}

\section{A. Binding of the minimum-strain $\mathrm{Cu}$ nanorods on $\mathrm{ZrO}_{2}$ supports}

To evaluate how the structure and position of a nanorod on a zirconia support influences the catalytic properties of the formed interface, we carefully analyzed the binding of the two nanorods by screening their positions on the zirconia. The heat-maps given in Fig. 2 show how the binding energy of a nanorod depends on its position on the surface. Specifically, we plot the relative energies of both (100) and (111) models with respect to their most stable structures on both tetragonal ( $\mathrm{a}$ and $\mathrm{b}$ ) and monoclinic ( $\mathrm{c}$ and $\mathrm{d}$ ) supports. We find that the variation of the nanorod position along its length has only a minor influence on the binding energy whereas moving the nanorod in the perpendicular direction across the zirconia surface introduces substantial energy changes. On $t-\mathrm{ZrO}_{2}$, the energy difference between the most stable and the least stable nanorod position is $1.4 \mathrm{eV}$ for the (100) model and $2.0 \mathrm{eV}$ for the (111) model. On $m-\mathrm{ZrO}_{2}$ the corresponding value is $2.2 \mathrm{eV}$ for both models.

We ascribe the large positional effect on the energy to the strong interaction between the bottom $\mathrm{Cu}$ atoms and the surface $\mathrm{O}$ anions. Figs. 1 and $\mathrm{S} 2$ display the energetically most favourable interface structures for the (100) and (111) models on both tetragonal and monoclinic zirconia. Careful visual inspection of the several interface structures indicate that the edge $\mathrm{Cu}$ atoms are attracted to surface oxygens and they avoid the positions directly above the $\mathrm{Zr}$ atoms. We anticipate that the positional effect would decrease with increasing nanorod width. The heat maps in Fig. 2 show that the favourable binding zone for $\mathrm{Cu}$ nanorods on zirconia is very narrow. Thus wider nanorods would always spread out over unfavourable areas of the zirconia as well, which weakens the overall binding to the underlying support. The fact that the relative energy increases steeply in heat maps when $\mathrm{Cu}$ atoms move to $\mathrm{Zr}$ top sites may also have implications for binding characteristics of larger $\mathrm{Cu}$ nanoparticles on zirconia. Interface structures, where the $\mathrm{Cu}$ edge atoms reside on Zr top sites should statistically appear less often as they are energetically costly and thus nanoparticles would prefer to create interfaces similar to those shown in Figs. 1 and S2 (For a top view of the binding interface, see Fig. S3).

More detailed comparison of energies of the two models shows that the (111) model is 


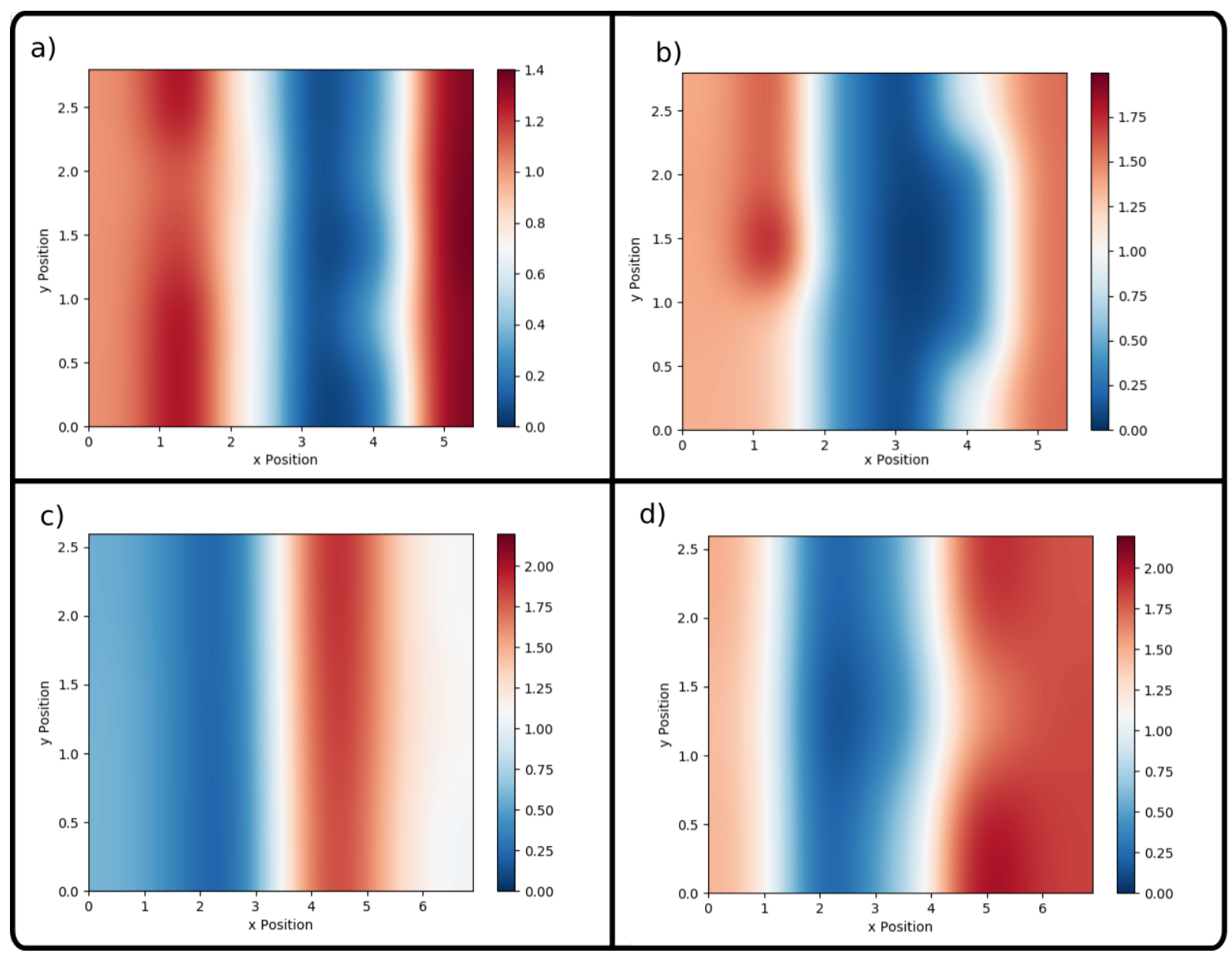

FIG. 2. Variation of the binding energy of a $\mathrm{Cu}$ nanorod across the studied zirconia surfaces: a) $(100) / t-\mathrm{ZrO}_{2}$, b) (111) $/ t-\mathrm{ZrO}_{2}$, c) $(100) / m-\mathrm{ZrO}_{2}$, and d) (111) $/ m-\mathrm{ZrO}_{2}$. The nanorods are oriented along the y-axis (vertical in the figure).

more stable than the (100) model. On $t-\mathrm{ZrO}_{2}$, the relative stability of the models differ by $0.11 \mathrm{eV}$ per nanorod unit, while on $m-\mathrm{ZrO}_{2}$ the difference as large as $0.32 \mathrm{eV}$. In the gas-phase, the (111) model is $0.33 \mathrm{eV} /$ nanorod unit more stable than the (100) model. However, as this energy difference decreases on the tetragonal zirocnia surface, it implies that the interaction with the support stabilises particularly the (100) Cu nanorod. We link the surface-specific stabilization effect to the $\mathrm{Cu}-\mathrm{O}$ distances, which are shorter on tetragonal zirconia than on monoclinic zirconia, see Fig. S4 a) and S5. The relative stabilities of (100) and (111) nanorods on zirconia surfaces are $0.37 \mathrm{eV} /$ nanorod unit and $0.24 \mathrm{eV} /$ nanorod unit, respectively and they further demonstrate the ability of the tetragonal surface to better stabilise $\mathrm{Cu}$ than the monoclinic surface. Even when considering the adsorption of a single 
$\mathrm{Cu}$ atom, we see that adsorption is about $0.3 \mathrm{eV}$ more exothermic on tetragonal zirconia. These are in line with a previous experimental study ${ }^{39}$, which reports stronger $\mathrm{Cu}-\mathrm{ZrO}_{2}$ interactions on tetragonal zirconia than on monoclinic. To gain more detail understanding for the energy variation seen in the heat map plots and to link the binding energy to the microscopic structure, we plotted the energy change with respect to the most stable (111)$\mathrm{ZrO}_{2}$ structure versus the average minimum $\mathrm{Cu}-\mathrm{O}$ distance between the bottom $\mathrm{Cu}$ atoms and topmost surface anions for different nanorod positions over both surfaces. Figs. S4 a and S5 clearly display that the (111) model is more stable than the (100) model and for both nanorod models the shorter distance corresponds to more stable structure. Furthermore,the average distance of the entire $\mathrm{Cu}$ nanorod (bottom) from the zirconia is $2.5 \AA$ on $t-\mathrm{ZrO}_{2}$ and $3.1 \AA$ on $m-\mathrm{ZrO}_{2}$. The shorter average $\mathrm{C}-\mathrm{O}$ distances and shorter nanorod-oxide distance can be explained with more exposed and symmetrically sitting lattice oxygens on the tetragonal surface. The optimization of bottom $\mathrm{Cu}$ atom positions with respect to surface oxygens is more challenging on the monoclinic surface owing to the larger asymmetry the surface and the fact that the surface anions are located deeper in the topmost surface layer. Additionally, we note that structural deformations in $\mathrm{Cu}$ nanorods originating from the interaction with the zirconia support show no correlation with the relative energy of the system as can be seen from Figure S4 b).

\section{B. Strain effects on nanorod binding}

A less optimal oxide surface cell size in calculations can introduce artificial strain effects on the nanorod and these, in turn, can influence the computed adsorption characteristics. Therefore, we analyzed strain effects more closely, for computational details see Table S2. First, the position of the differently strained nanorods were screened over both zirconia surfaces. We find that the preferred nanorod positions are almost identical to those given in Figs. 1, S2, and S3 for the ideal interfaces, and thus we limit our study on the most stable nanorod positions. In particular, we aim to understand changes in nanorod binding energies due to strain and elucidate the difference between the tetragonal and monoclinic $\mathrm{ZrO}_{2}$ surfaces with special emphasis on the tetragonal surface.

The last column in Table I shows that the total binding energy $\left(\Delta E_{b}\right)$ is more exothermic

for the (100) model and the tetragonal surface than for the (111) model and the monoclinic 


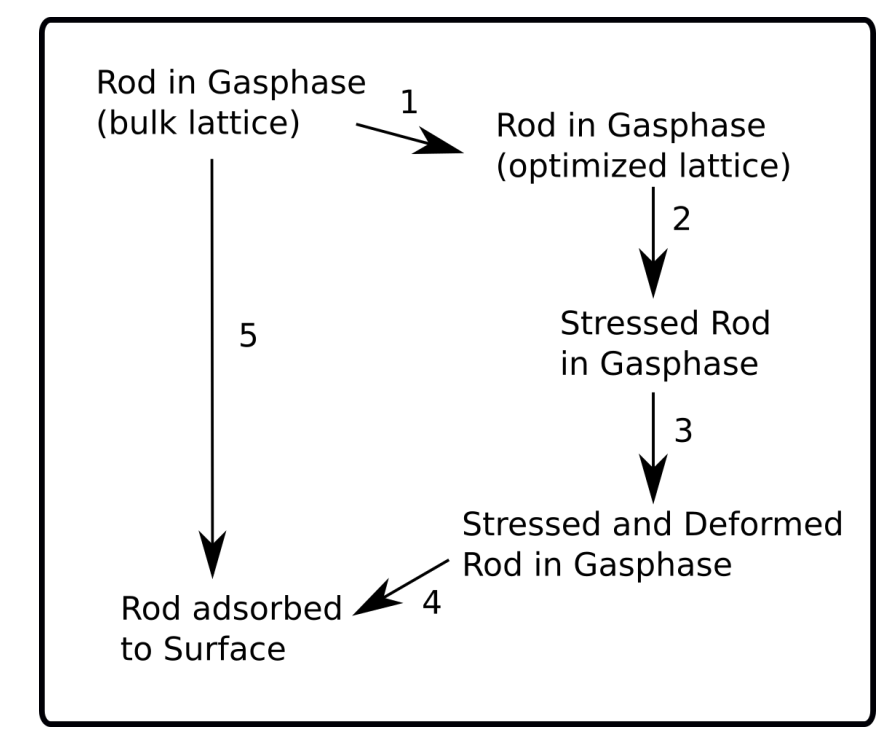

FIG. 3. A thermodynamic cycle for the binding energy decomposition for a $\mathrm{Cu}$ nanorod on $\mathrm{ZrO}_{2}$.

surface, but it follows no obvious trend. To understand the origin of this variation better, the thermodynamic cycle (see schematic Figure 3) was devised to analyse the different components. The cycle divides the $\mathrm{Cu}-\mathrm{ZrO}_{2}$ binding energy into four contributions. The first three steps constitute the changes in the gas-phase nanorod and the last one measures the pure electronic interaction with zirconia. Step 1 describes the change for the optimisation of interatomic $\mathrm{Cu}-\mathrm{Cu}$ distances whereas step 2 gives the energy change originating from strain effects and step 3 represents the energy change due to structure deformation arising from the interaction between the nanorod and zirconia. The remaining contribution, step 4, defines the pure electronic binding interaction between the deformed $\mathrm{Cu}$ nanorod and zirconia.

The energy changes accompanying the thermodynamic steps are collected in Table I. Overall the contributions from steps 1-3 are small compared to step 4, which dominates. The slight energy decrease seen in step 1 for all the models indicates that the Cu bulk lattice constant is not optimal for the gas-phase nanorod. In fact, the $\mathrm{Cu}-\mathrm{Cu}$ distance decreases from the bulk value $2.61 \AA$ to $2.58 \AA$ for both nanorod models on $m$-ZrO2 $2_{2}$, and to 2.55 (2.57) $\AA$ for the (100) model ((111) model) on $t$-ZrO2 2 . Other minor variations in $\mathrm{Cu}-\mathrm{Cu}$ distances and energies in step 1 originate from the differences in the computational cell shapes. As expected, increasing strain leads to positive (endothermic) energy change in step 2 as mainly also does nanorod deformation in step 3. While irregularities introduced by the support make it difficult to predict clear trends, the larger strain is accompanied by 
TABLE I. Nanorod binding energies (in $\mathrm{eV}$ ) at each stage of the thermodynamic cycle shown in Fig. 3. $\Delta E_{b}$ stands for binding energy of a nanorod to the zirconia surface and step5 in the thermodynamic cycle. To facilitate comparison, the energies are divided by the number of rod units in the corresponding cell.

\begin{tabular}{|c|c|c|c|c|c|c|}
\hline $\mathrm{ZrO}_{2}$ & Nanorod & Strain $(\%)$ & Step 1 Step 2 & Step 3 & Step 4 & $\Delta E_{b}$ \\
\hline \multirow{10}{*}{$t-\mathrm{ZrO}_{2}$} & \multirow{5}{*}{$(100)$} & -7.34 & $-0.034+0.159$ & -0.363 & -1.069 & -1.306 \\
\hline & & -2.71 & $-0.034+0.002$ & -0.005 & -1.025 & -1.061 \\
\hline & & -0.72 & $-0.034+0.021$ & +0.007 & -1.108 & -1.113 \\
\hline & & +4.24 & $-0.034+0.220$ & +0.014 & -1.183 & -0.983 \\
\hline & & +8.10 & $-0.034+0.456$ & +0.055 & -1.256 & -0.779 \\
\hline & \multirow{5}{*}{$(111)$} & -7.34 & $-0.012+0.205$ & -0.199 & -0.871 & -0.877 \\
\hline & & -2.71 & $-0.012+0.003$ & +0.035 & -0.994 & -0.968 \\
\hline & & -0.72 & $-0.012+0.008$ & +0.102 & -1.010 & -0.912 \\
\hline & & +4.24 & $-0.012+0.168$ & +0.045 & -1.039 & -0.838 \\
\hline & & +8.10 & $-0.012+0.390$ & +0.120 & -1.136 & -0.638 \\
\hline \multirow{4}{*}{$m-\mathrm{ZrO}_{2}$} & $(100)$ & -1.02 & $-0.019+0.008$ & +0.067 & -0.787 & -0.741 \\
\hline & \multirow{3}{*}{$(111)$} & -4.02 & $-0.012+0.035$ & +0.002 & -0.714 & -0.579 \\
\hline & & -1.02 & $-0.012+0.001$ & +0.009 & -0.743 & -0.673 \\
\hline & & +5.57 & $-0.012+0.225$ & +0.072 & -0.898 & -0.667 \\
\hline
\end{tabular}

stronger deformation and this is especially clear for the two most strained (100) rods.

$\mathrm{Cu}$ nanorod binding energy on zirconia is dominated by electronic interaction (step 4), which is more exothermic for $t-\mathrm{ZrO}_{2}$ than for $m-\mathrm{ZrO}_{2}$ resulting most likely from the shorter $\mathrm{Cu}-\mathrm{O}$ distance as suggested also for the minimum strain interfaces. As illustrated in Fig. S6, the introduced strain correlates well with the electronic interaction energy, where the compression of the nanorod decreases the electronic interaction between $\mathrm{Cu}$ and zirconia, while the expansion of the nanorod enhances it. No clear correlation is seen when attempting to link binding energies to strain. Multiple factors may contribute to this, the main reason being the irregular structural deformations during structure optimization. The d-band-center analysis supports the stronger interaction between $\mathrm{Cu}$ and tetragonal zirconia as the shifts in the d-band center are larger for tetragonal than monoclinic surfaces. The net shift, see 


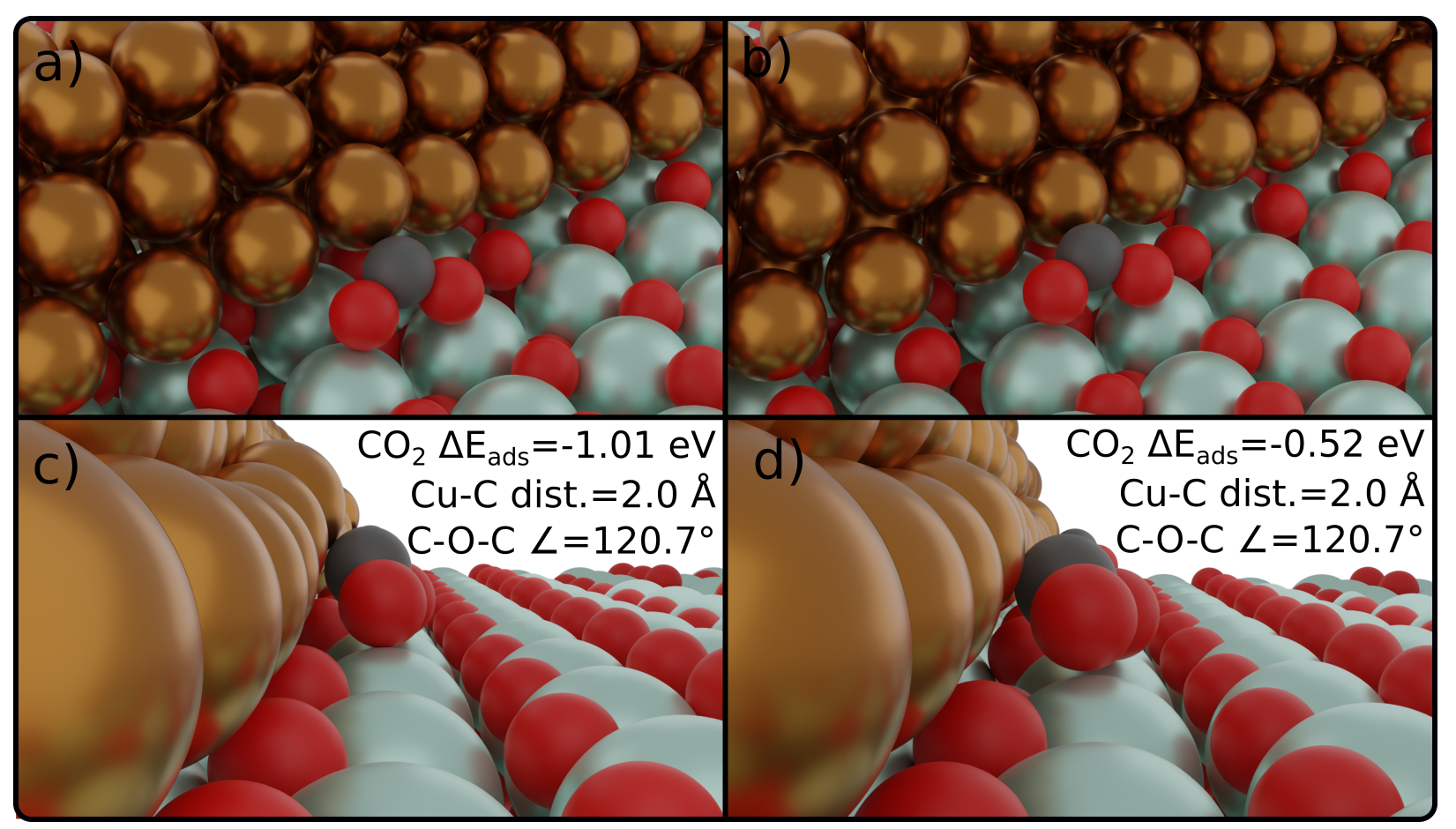

FIG. 4. Front and side views of the most stable $\mathrm{CO}_{2}$ adsorption geometry at the minimum-strain $\mathrm{Cu}-t-\mathrm{ZrO}_{2}$ interfaces for the (100) model (panels a and c) and the (111) model (b and d).

Table S3, is to lower energies and it is dominated by the "ligand" effect introduced by the oxide, whereas the "strain" effect, including deformation, constitutes minor contribution.

\section{C. $\mathrm{CO}_{2}$ adsorption and activation}

In order to estimate the significance of an interface site to $\mathrm{CO}_{2}$ adsorption and activation, we conducted a thorough screening of the available sites for the structures explored in section III A. We find that the $\mathrm{CO}_{2}$ adsorbs preferably in a bent configuration for the minimumstrain interface structures as shown in Figs. 4 and 5. Our results also demonstrate that adsorption energies depend sensitively on the nanorod model and the interface structure.

Figure 4 displays the minimum-strain $\mathrm{Cu}-t-\mathrm{ZrO}_{2}$ interface for which the most exothermic $\mathrm{CO}_{2}$ adsorption energies were computed to be -1.01 and $-0.52 \mathrm{eV}$ for the (100) and (111) models, respectively. The adsorption energies for other interfacial sites along these interfaces can be found from Table S4. A previous DFT study ${ }^{26}$ reports as large as a $-1.78 \mathrm{eV}$ adsorption energy for the $\mathrm{CO}_{2}$ with the (100) model. We associate the large difference with two factors, firstly a $+0.41 \mathrm{eV}$ gas-phase correction was applied to $\mathrm{CO}_{2},{ }^{26}$, and secondly, to 


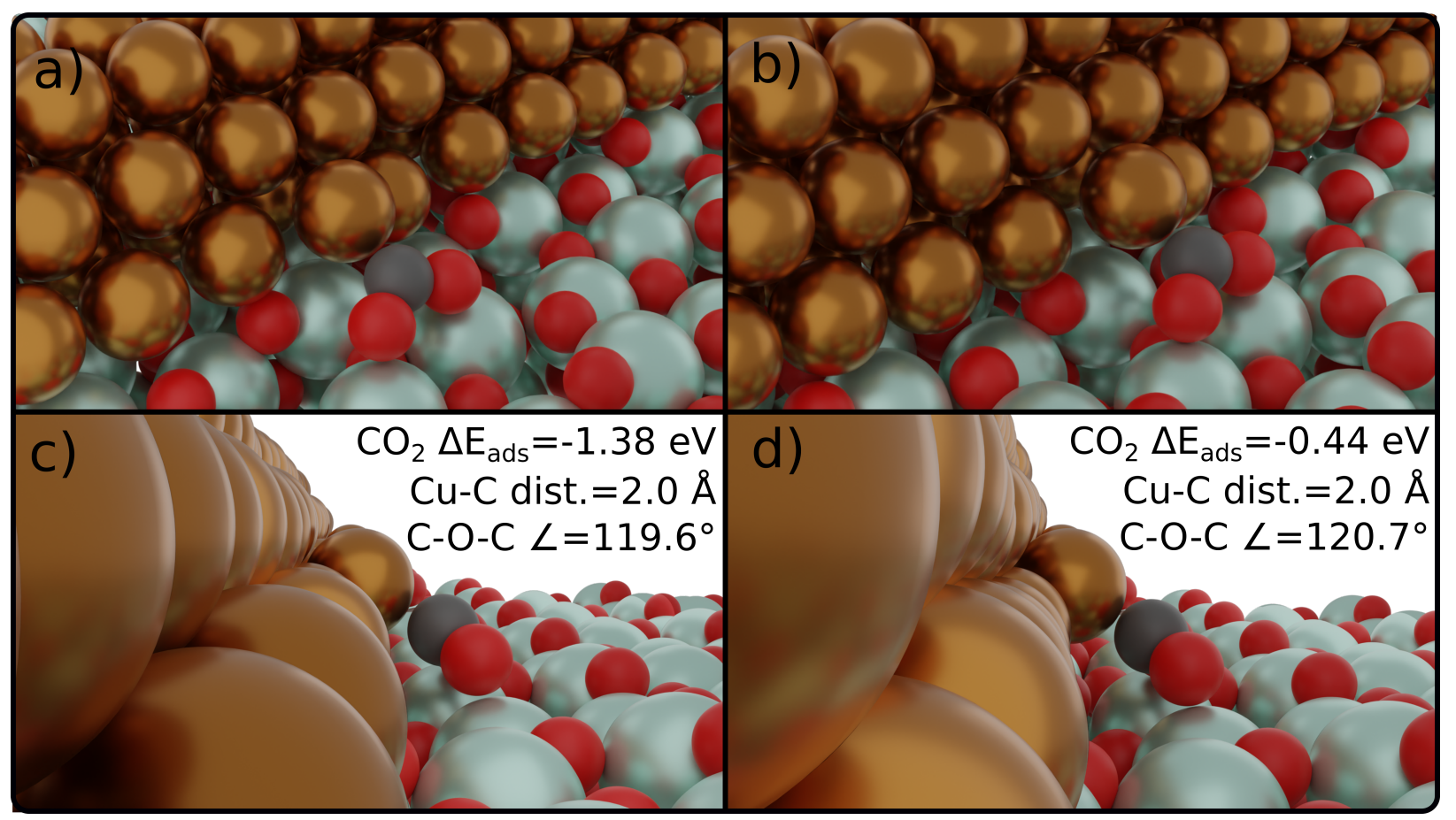

FIG. 5. Front and side views of the most stable $\mathrm{CO}_{2}$ adsorption geometry at the minimum-strain $\mathrm{Cu}-m-\mathrm{ZrO}_{2}$ interfaces for the (100) model (panels a and c) and the (111) model (b and d).

the fact that the employed interface model has substantial, $5.08 \%$, strain, which strongly impacts $\mathrm{CO}_{2}$ adsorption as discussed below. Figure 5 illustrates the $\mathrm{CO}_{2}$ adsorption on the $\mathrm{Cu}-m-\mathrm{ZrO} \mathrm{r}_{2}$ interface, where the computed $\mathrm{CO}_{2}$ adsorption energies are $-1.38 \mathrm{eV}$ for the (100) nanorod and $-0.44 \mathrm{eV}$ for the (111) nanorod. For a $\mathrm{Cu}_{38}-m-\mathrm{ZrO}_{2}(\overline{1} 11)$ interface, $\mathrm{CO}_{2}$ absorption energy is $-1.86 \mathrm{eV}^{8}$ being substantially more exothermic than what we found in this work. This time, the observed adsorption energy difference is attributed on one hand to the different exchange and correlation functional, and on the other hand to the 38-atom cluster geometry. In another computational work, an adsorption energy of $-0.69 \mathrm{eV}$ was reported for a slightly thinner (111)-type $\mathrm{Cu}$ nanorod on a stepped $m-\mathrm{ZrO}_{2}(\overline{2} 12)$ surface, ${ }^{7}$ where the $\mathrm{CO}_{2}$ is at the interface but binds only to the $\mathrm{Cu}$ atoms.

The most stable $\mathrm{CO}_{2}$ adsorption geometries are structurally similar for both zirconia surfaces and nanorod models. $\mathrm{CO}_{2}$ prefers a bidendate geometry, i.e., it binds to the $\mathrm{Cu}$ via the carbon atom and has both oxygen atoms pointing down towards the support cations with the O-C-O angle being close to $120^{\circ}$. A substantial deviation from the linear gasphase structure and a slight, $0.14 \AA$, elongation of the $\mathrm{C}-\mathrm{O}$ bonds clearly indicate $\mathrm{CO}_{2}$ activation. This is further supported by the Bader charge analysis showing that the $\mathrm{CO}_{2}$ 
molecule gains $1.2|e|$ upon adsorption, which is in line with the previously reported value. ${ }^{8}$ Interaction between $\mathrm{CO}_{2}$ and the interface introduces structural deformations to the $\mathrm{Cu}$ nanorods. While in the case of the $t-\mathrm{ZrO}_{2}$ surface, the distortion of $\mathrm{Cu}$ edge is minor, on $m-\mathrm{ZrO}_{2} \mathrm{CO}_{2}$ clearly pulls out one $\mathrm{Cu}$ atom from the both nanorods, see Fig. 5 .

Table II summarizes the energy contributions defined in Eqs. (1)-(5) and displays the origin of the variation of $\mathrm{CO}_{2}$ adsorption energies from one minimum-strain interface to the other. We first focus on electronic interaction energies, which exclude all the structural deformations. For example, the adsorption energy difference $\left(\Delta \Delta E_{\text {ads }}\right)$ between the $(100)$ and (111) models is $0.49 \mathrm{eV}$ for the tetragonal surface, whereas the pure electronic, aka binding, interaction energy difference, $\Delta \Delta E_{\mathrm{el}}^{\text {tot }}$, shows a larger, $0.75 \mathrm{eV}$, value. Interestingly, for the monoclinic surface $\Delta \Delta E_{\text {ads }}$ is larger than $\Delta \Delta E_{\mathrm{el}}^{\text {tot }}(0.9$ vs $0.5 \mathrm{eV})$. The opposite behaviour is ascribed to nonidentical atomic relaxations for different $\mathrm{CO}_{2}$-interface systems. In general, we attribute the observed adsorption energy differences to different electronic interaction energies, which are clearly more exothermic for the (100) model on both tetragonal and monoclinic zirconia. The interaction energies from the $\mathrm{CO}_{2}-\mathrm{Cu}$ and $\mathrm{CO}_{2}-\mathrm{ZrO}_{2}$ subsystems, which measure the binding between $\mathrm{CO}_{2}$ and metal and $\mathrm{CO}_{2}$ and oxide, do not indicate that one nanorod model or zirconia crystal structure is favoured over the other. The substantial synergy between the $\mathrm{Cu}$ and zirconia is demonstrated by the exothermic values of $\Delta E_{\text {exc }}$ for all the studied system.

Next, a $\mathrm{CO}_{2}$ adsorption site at the (111)- $\mathrm{ZrO}_{2}$ interface is further explored by moving the nanorod across the oxide surfaces. Fig. 6 displays the heat maps summarizing the energy variation with respect to the most stable adsorption structure at the interface. The plots show, that for many nanorod positions, $\mathrm{CO}_{2}$ does not either adsorb at all or adsorption is energetically very unfavourable. In order to interpret the heat map information, we analyzed the calculated $\mathrm{CO}_{2}$ adsorption structures. For a favourable $\mathrm{CO}_{2}$ adsorption, it seems to be crucial to have lattice Zr cations sufficiently close to the $\mathrm{Cu}$ edge to ensure that the oxygens of the $\mathrm{CO}_{2}$ molecule can interact with them. The nanorod positions, where surface anions are closer to the $\mathrm{Cu}$ edge than the $\mathrm{Zr}$ cations lead to unfavourable $\mathrm{CO}_{2}$ adsorption due to repulsive interactions between the oxygen atoms and anions. The central role of the zirconia support is further highlighted by the fact that, without the support, $\mathrm{CO}_{2}$ only physisorbs maintaining a linear structure on a $\mathrm{Cu}(111)$ surface as well as on our (111) and (100) nanorods. This agrees well with the previous DFT results, which also demonstrate 
TABLE II. $\mathrm{CO}_{2}$ adsorption energies $\left(\Delta E_{\text {ads }}\right)$ and electronic interaction energies $\left(\Delta E_{\mathrm{el}}^{\mathrm{tot}}, \Delta E_{\mathrm{el}}^{\mathrm{Cu}}\right.$, $\Delta E_{\mathrm{el}}^{\mathrm{Zr}}$, and $\left.\Delta E_{\mathrm{exc}}\right)$, defined in Eqs. (2)-(5) for different models and strain values. All the energy values are given in $\mathrm{eV}$.

\begin{tabular}{|c|c|c|c|c|c|c|}
\hline $\mathrm{ZrO}_{2}$ & nanorod & Strain (\%) & $\Delta E_{\text {ads }} \Delta E_{\mathrm{el}}^{\mathrm{tot}}$ & $\Delta E_{\mathrm{el}}^{\mathrm{Cu}}$ & $\Delta E_{\mathrm{el}}^{\mathrm{Zr}}$ & $\Delta E_{\text {exc }}$ \\
\hline \multirow{7}{*}{$t-\mathrm{ZrO}_{2}$} & \multirow{2}{*}{$(100)$} & -0.72 & $-1.01-6.30$ & -2.49 & -1.76 & -2.05 \\
\hline & & +4.24 & $-1.17-6.39$ & -2.86 & -1.63 & -1.89 \\
\hline & \multirow{5}{*}{$(111)$} & -7.34 & $-1.91-6.02$ & -2.34 & -1.55 & -2.13 \\
\hline & & -2.71 & $-0.51-5.84$ & -2.38 & -1.85 & -1.60 \\
\hline & & -0.72 & $-0.52-5.55$ & -2.58 & -1.50 & -1.47 \\
\hline & & +4.24 & $-0.71-5.98$ & -2.49 & -1.63 & -1.87 \\
\hline & & +8.10 & $-1.33-6.27$ & -2.17 & -1.39 & -2.71 \\
\hline \multirow{4}{*}{$m-\mathrm{ZrO}_{2}$} & $(100)$ & -1.02 & $-1.38-6.06$ & -2.13 & -1.63 & -2.30 \\
\hline & \multirow{3}{*}{$(111)$} & -4.02 & $-0.89-5.79$ & -1.88 & -1.72 & -2.18 \\
\hline & & -1.02 & $-0.44-5.57$ & -1.78 & -1.62 & -2.18 \\
\hline & & +5.57 & $-1.34-5.81$ & -2.69 & -1.70 & -1.42 \\
\hline
\end{tabular}

$\mathrm{CO}_{2}$ physisorption on $\mathrm{Cu}(111)$ and $\mathrm{Cu}(533)$ surfaces. $^{28,37}$

$\mathrm{CO}_{2}$ adsorption on the bare zirconia surface leads to carbonate $\left(\mathrm{CO}_{3}\right)$ formation with the lattice oxygen. We find this process exothermic by $-0.57 \mathrm{eV}$ on $t-\mathrm{ZrO}_{2}$ and by $-0.59 \mathrm{eV}$ on $m-\mathrm{ZrO}_{2}$. In the case of a (111) model, the carbonate formation is thermodynamically slightly more favourable than $\mathrm{CO}_{2}$ adsorption at the interface, which makes these two simultaneous reactions competing. On the other hand, $\mathrm{CO}_{2}$ adsorption at the interface is clearly preferred to carbonate formation for the (100) model. Previously computed ${ }^{62}$ carbonate formation energy on the same monoclinic zirconia surface is about $-1.13 \mathrm{eV}$, which is substantially more exothermic than the value reported here. We ascribe this energy difference to the different exchange and correlation functional and to the thicker zirconia slab, not computationally feasible for the present screening study. Note that under the reaction conditions, zirconia is partially covered by $\mathrm{OH}$ groups, which are known to react with $\mathrm{CO}_{2}$ to create an extremely stable formate species. ${ }^{6,13,62,63}$

We close the discussion on $\mathrm{CO}_{2}$ adsorption and activation by considering that at the strained metal-oxide interfaces. Similar to the minimum-strained nanorods, $\mathrm{CO}_{2}$ is acti- 


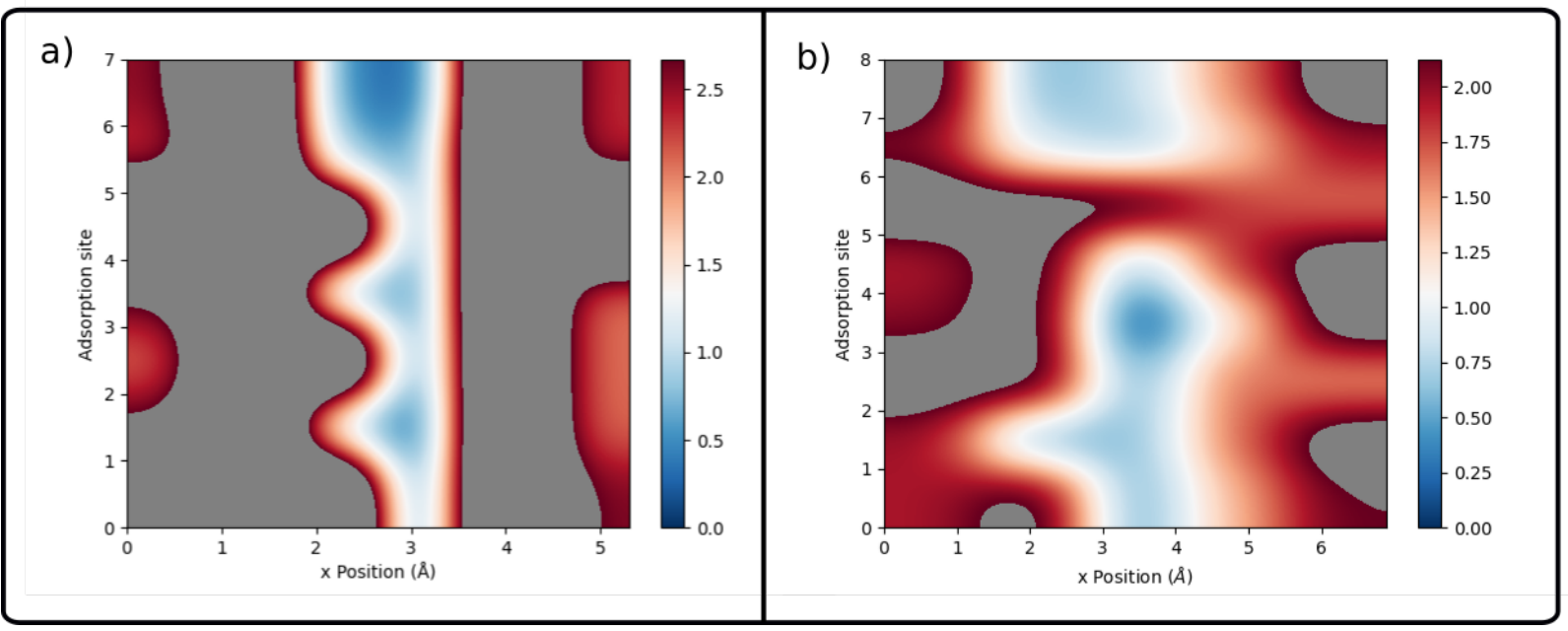

FIG. 6. Heat maps for $\mathrm{CO}_{2}$ adsorption upon varying the position of the (111) nanorod across the a) $t-\mathrm{ZrO}_{2}$ and b) $m-\mathrm{ZrO}_{2}$ surfaces. The nanorod lies parallel to the vertical axis and is moved along the horizontal axis. The energy difference is given with respect to the most stable adsorption structure. The vertical axis numbers represent $\mathrm{Cu}$ edge atoms to which $\mathrm{CO}_{2}$ was attempted to bind. Gray color corresponds to the nanorod positions, which do not bind or activate $\mathrm{CO}_{2}$.

vated via electron transfer and the molecule adopts a bent adsorption configuration. The bidentate binding is preferred, while monodentate geometries also appear at slightly higher energies. $\mathrm{CO}_{2}$ adsorption energies and the electronic interaction energy components for the strained interfaces are presented in Table II. While the data does not allow to make comprehensive conclusions for all the interfaces, we can say that for the (111) model the straining and compressing of the nanorod leads to more exothermic electronic interaction energies. However, one has to be careful with the nanorods exposed to larger $( \pm>7 \%)$ strain, as they experienced significant structural deformations during the atomic structure optimization, which reduced the atomic coordination number of some $\mathrm{Cu}$ atoms, typically those interacting with the $\mathrm{C}$ atom leading to enhanced $\mathrm{CO}_{2}$ adsorption. Therefore, these systems are largely omitted from the detailed discussion. In general, adsorption and total electronic interaction energies do not correlate. This means that adsorption energy difference and total electronic interaction energy difference, $\Delta \Delta E_{\text {ads }}$ and $\Delta \Delta E_{\mathrm{el}}^{\mathrm{tot}}$, differ for a considered system pair. Again, this can be attributed to diverse deformations of the nanorod and the molecule giving system-specific positive deformation energies. In addition, we see for all the systems strong synergy between metal and oxide, which is reflected by exothermic values of 
$\Delta E_{\text {exc }}$ and highlights the unique nature of the interface. Table II also shows that interfaces built from the (100) nanorod give more exothermic $\mathrm{CO}_{2}$ adsorption energies than its (111) counterpart.

In order to understand the variation of $\mathrm{CO}_{2}$ adsorption energy from one system to the other, we performed d-band center analysis separately to each steps in the thermodynamic cycle. The formation of a metal-oxide interface has been considered as a two-step process ${ }^{25}$ including the "strain" and "ligand" contributions similar to bimetallic systems. ${ }^{64}$ The "strain effects include both changes in $\mathrm{Cu}-\mathrm{Cu}$ distances along the nanorod as well as structural deformation of the nanorod due to interaction with zirconia whereas the ligand effect describes the electronic interactions between $\mathrm{Cu}$ and zirconia. The first three steps in the thermodynamic cycle contribute to the shift of the d-band center due to strain effects $\Delta \epsilon_{d}^{\text {strain }}$ while the shift of the d-band center for step $4\left(\Delta \epsilon_{d}^{\text {ligand }}\right)$ measures the change resulting from the ligand effect. The overall impact of the support to the $\mathrm{Cu}$ nanorod is a clear shift of a dband center to lower energies for all the models, see Table S3 explicit numerical values. The ligand effects clearly dominate and the negative value of $\Delta \epsilon_{d}^{\text {ligand }}$ for all the interface models highlight that binding interaction between the $\mathrm{Cu}$ and zirconia shifts the d-band center to lower energies. The contribution of the strain effects to the shift of the d-band center is negligible being positive for some interfaces and negative for some others. Table S3 shows that $\mathrm{CO}_{2}$ adsorption energies can not be rationalized with the shift of the d-band center as no correlation can be established between the adsorption energy and the total shift in the d-band center. We believe that the complex metal-oxide interaction effects at the interface together with structural deformations, especially in the case of the less stable (100) rod, make the d-band model insufficient to explain $\mathrm{CO}_{2}$ adsorption energies.

Altogether, our DFT results highlight that $\mathrm{CO}_{2}$ adsorption and activation depends sensitively on the atomic structure and composition making only few site geometries favourable for $\mathrm{CO}_{2}$. Moreover, care must be taken when building computational interface models as artificial strain enhances $\mathrm{CO}_{2}$ adsorption and similar effects might be present for reaction intermediates as well, let alone that the possible strain effects may affect the activation barriers for elementary steps taking place at the interface. Structure sensitivity of $\mathrm{CO}_{2}$ adsorption suggests that not all the $\mathrm{Cu}-\mathrm{ZrO}_{2}$ interfaces at real-world catalytic systems are active towards $\mathrm{CO}_{2}$ chemistry. This is because supported nanoparticles present various interface sites with different composition and atomic structure and their direct structural 
optimization is infeasible.

\section{CONCLUSIONS}

We have investigated the properties of a $\mathrm{Cu}-\mathrm{ZrO}_{2}$ interface and its ability to adsorb and activate $\mathrm{CO}_{2}$ using density functional theory calculations. Specifically, two $\mathrm{Cu}$ nanorod models were explored on $m-\mathrm{ZrO}_{2}(\overline{111})$, and $t-\mathrm{ZrO}_{2}(101)$ surfaces. We observed that the (111) nanorod model is always more stable than the (100) one regardless of whether it is supported by zirconia or not. Tetragonal $\mathrm{ZrO}_{2}$ stabilises both nanorod models more than the monoclinic $\mathrm{ZrO}_{2}$, which is likely due to the more exposed oxygen anions of the $t-\mathrm{ZrO}_{2}(101)$ surface. Our calculations demonstrate that the stability of the nanorod depends sensitively on its local chemical environment on $\mathrm{ZrO}_{2}$ and results from the fact that $\mathrm{Cu}$ atoms avoid the interaction with surface cations and prefer to minimize a $\mathrm{Cu}$-anion nearest neighbour distance. Compression along the nanorod enhances binding to the zirconia while tension of the nanorod weakens the interaction with the studied oxide surfaces.

Our results demonstrate that the employed $\mathrm{Cu}-\mathrm{ZrO}_{2}$ interface model significantly impacts the adsorption characteristics of the $\mathrm{CO}_{2}$ molecule. In general, the interfaces built using the (100) nanorod adsorb $\mathrm{CO}_{2}$ more strongly compared to the interfaces created with the (111) nanorods. The activation of $\mathrm{CO}_{2}$ is seen as increased Bader charge and a bent adsorption

configuration. Applying strain to the nanorod enhances electronic interaction with the $\mathrm{CO}_{2}$, which is not always reflected in more exothermic adsorption energies due to structural deformation effects. The excess interaction energy originating from the synergy between the metal and the support is strongly exothermic for the all studied systems, highlighting the importance of the meal-oxide interface. Furthermore, depending on how the nanorod is positioned on the $\mathrm{ZrO}_{2}, \mathrm{CO}_{2}$ might not adsorb at the interface at all.

Overall, not only the chemical composition but also the diverse structural features of an interface can impact the adsorption characteristics of reacting molecules and consequently the computed activity and selectivity profiles. Therefore, when building computational models for catalytic reactions taking place at the metal-oxide interface, care should be taken in constructing interfaces and identifying interfacial active sites. 


\section{SUPPLEMENTARY MATERIAL}

See supplementary material for details on the construction and the structure of the atomic models, and the d-band shifts for the thermodynamic cycle.

\section{ACKNOWLEDGMENTS}

The work was funded by Academy of Finland projects 329977 and 307623 and University of Jyväskylä. The electronic structure calculations were made possible by the computational resources provided by the CSC - IT Center for Science, Espoo, Finland (https://www.csc.fi/en/) and Finnish Grid and Cloud Infrastructure.

\section{DATA AVAILABILITY}

The data that support the findings of this study are available from the corresponding author upon reasonable request. 


\section{REFERENCES}

${ }^{1}$ S. Roy, A. Cherevotan, and S. C. Peter, ACS Ener. Lett. 3, 1938 (2018).

${ }^{2}$ B. M. Tackett, E. Gomez, and J. G. Chen, Nat. Catal. 2, 381 (2019).

${ }^{3}$ R. P. Ye, J. Ding, W. Gong, M. D. Argyle, Q. Zhong, Y. Wang, C. K. Russell, Z. Xu, A. G. Russell, Q. Li, M. Fan, and Y. G. Yao, Nat. Comm. 10, 5698 (2019).

${ }^{4}$ S. Kattel, P. J. Ramírez, J. G. Chen, J. A. Rodriguez, and P. Liu, Science 355, 1296 (2017).

${ }^{5}$ S. Kattel, P. Liu, and J. G. Chen, J. Am. Chem. Soc. 139, 9739 (2017).

${ }^{6}$ N. Scotti, F. Bossola, F. Zaccheria, and N. Ravasio, Catalysts 10, 168 (2020).

${ }^{7}$ Q.-L. Tang, Q.-J. Hong, and Z.-P. Liu, J. Catal. 263, 114 (2009).

${ }^{8}$ K. Larmier, W.-C. C. Liao, S. Tada, E. Lam, R. Verel, A. Bansode, A. Urakawa, A. ComasVives, and C. Copéret, Angew. Chem. Int. Ed. 56, 2318 (2017).

${ }^{9}$ M. Zabilskiy, V. L. Sushkevich, D. Palagin, M. A. Newton, F. Krumeich, and J. A. van Bokhoven, Nat. Comm. 11, 2409 (2020).

${ }^{10}$ Y. Wang, S. Kattel, W. Gao, K. Li, P. Liu, J. G. Chen, and H. Wang, Nat. Comm. 10, 1166 (2019).

${ }^{11}$ Q. Fu and T. Wagner, Surf. Sci. Rep. 62, 431 (2007).

${ }^{12}$ Z.-J. Zhao, Z. Li, Y. Cui, H. Zhu, W. F. Schneider, W. N. Delgass, F. Ribeiro, and J. Greeley, J. Catal. 345, 157 (2017).

${ }^{13}$ M. M. Kauppinen, M. M. Melander, A. S. Bazhenov, and K. Honkala, ACS Catal. 8, 11633 (2018).

${ }^{14}$ Y. Y. Wu, N. A. Mashayekhi, and H. H. Kung, Catal. Sci. Technol. 3, 2881 (2013).

${ }^{15}$ I. X. Green, W. Tang, M. Neurock, and J. T. Yates, Science 333, 736 (2011).

${ }^{16}$ M. Boronat and A. Corma, Dalton Trans. 39, 8538 (2010).

${ }^{17}$ P. Schlexer, D. Widmann, R. J. Behm, and G. Pacchioni, ACS Catal. 8, 6513 (2018).

${ }^{18}$ H. Tao, C. Choi, L.-X. Ding, Z. Jiang, Z. Hang, M. Jia, Q. Fan, Y. Gao, H. Wang, A. W. Robertson, S. Hong, Y. Jung, S. Liu, and Z. Sun, Chem 5, 204 (2019).

${ }^{19}$ Q. Fu, W.-X. Li, Y. Yao, H. Liu, H.-Y. Su, D. Ma, X.-K. Gu, L. Chen, Z. Wang, H. Zhang, B. Wang, and X. Bao, Science 328, 1141 (2010).

${ }^{20}$ J.-Y. Luo, M. Meng, X. Li, X.-G. Li, Y.-Q. Zha, T.-D. Hu, Y.-N. Xie, and J. Zhang, J. Catal. 254, 310 (2008). 
${ }^{21}$ J. Shen, R. E. Hayes, and N. Semagina, Catal. Today 360, 435 (2021).

${ }^{22}$ N. T. S. Phan, M. Van Der Sluys, and C. W. Jones, Adv. Synt. Catal. 348, 609 (2006).

${ }^{23}$ V. Polshettiwar, C. Len, and A. Fihri, Coordin. Chem. Rev. 253, 2599 (2009).

${ }^{24}$ Z.-c. Zhang, B. Xu, and X. Wang, Chem. Soc. Rev. 43, 7870 (2014).

${ }^{25}$ P. Mehta, J. Greeley, W. N. Delgass, and W. F. Schneider, ACS Catal. 7, 4707 (2017).

${ }^{26}$ S. Polierer, J. Jelic, S. Pitter, and F. Studt, J. Phys. Chem. C 123, 26904 (2019).

${ }^{27}$ J. K. Nørskov, T. Bligaard, J. Rossmeisl, and C. H. Christensen, Nat. Chem. 1, 37 (2009).

${ }^{28}$ D. Kopač, B. Likozar, and M. Huš, Appl. Surf. Sci. 497, 143783 (2019).

${ }^{29}$ I. A. Pašti and S. V. Mentus, Electrochim. Acta 55, 1995 (2010).

${ }^{30}$ M. Mavrikakis, B. Hammer, and J. K. Nørskov, Phys. Rev. Lett. 81, 2819 (1998).

${ }^{31}$ S. Kattel, B. Yan, J. G. Chen, and P. Liu, J. Catal. 343, 115 (2016).

${ }^{32}$ M. M. Kauppinen, V. Korpelin, A. M. Verma, M. M. Melander, and K. Honkala, J. Chem. Phys 151, 164302 (2019).

${ }^{33}$ A. S. Bazhenov and K. Honkala, J. Phys. Chem. C 123, 7209 (2019).

${ }^{34}$ Y. Yang, J. Evans, J. A. Rodriguez, M. G. White, and P. Liu, Phys. Chem. Chem. Phys. 12, 9909 (2010).

${ }^{35}$ G. A. Olah, Angew. Chem. Int. Ed. 52, 104 (2013).

${ }^{36}$ M. Behrens, F. Studt, I. Kasatkin, S. Kuhl, M. Havecker, F. Abild-Pedersen, S. Zander, F. Girgsdies, P. Kurr, B.-L. Kniep, M. Tovar, R. W. Fischer, J. K. Nørskov, and R. Schlögl, Science 336, 893 (2012).

${ }^{37}$ L. C. Grabow and M. Mavrikakis, ACS Catal. 1, 365 (2011).

${ }^{38}$ S. Kattel, B. Yan, Y. Yang, J. G. Chen, and P. Liu, J. Am. Chem. Soc. 138, 12440 (2016).

${ }^{39}$ T. Witoon, J. Chalorngtham, P. Dumrongbunditkul, M. Chareonpanich, and J. Limtrakul, Chem. Eng. J. 293, 327 (2016).

${ }^{40}$ Y. Nitta, O. Suwata, Y. Ikeda, Y. Okamoto, and T. Imanaka, Catal. Lett. 26, 345 (1994).

${ }^{41}$ K. D. Jung and A. T. Bell, J. Catal. 193, 207 (2000).

${ }^{42}$ I. A. Fisher and A. T. Bell, J. Catal. 178, 153 (1998).

${ }^{43}$ I. A. Fisher, H. C. Woo, and A. T. Bell, Catal. Lett. 44, 11 (1997).

${ }^{44}$ F. Arena, G. Italiano, K. Barbera, S. Bordiga, G. Bonura, L. Spadaro, and F. Frusteri, Appl. Catal. A Gen. 350, 16 (2008).

${ }^{45}$ F. Arena, G. Mezzatesta, G. Zafarana, G. Trunfio, F. Frusteri, and L. Spadaro, J. Catal. 300, 141 (2013). 
${ }^{46}$ J. D. Grunwaldt, A. M. Molenbroek, N. Y. Topsøe, H. Topsøe, and B. S. Clausen, J. Catal. 194, 452 (2000).

${ }^{47}$ A. Le Valant, C. Comminges, C. Tisseraud, C. Canaff, L. Pinard, and Y. Pouilloux, J. Catal. 324, 41 (2015).

${ }^{48}$ J. Zhong, X. Yang, Z. Wu, B. Liang, Y. Huang, and T. Zhang, Chem. Soc. Rev. 49, 1385 (2020).

${ }^{49}$ I. X. Green, W. Tang, M. Neurock, and J. T. Yates Jr., Angew. Chem. Int. Edit. 50, 10186 (2011).

${ }^{50}$ I. Kasatkin, P. Kurr, B. Kniep, A. Trunschke, and R. Schlögl, Angew. Chem. Int. Ed. 46, 7324 (2007).

${ }^{51}$ M. M. Günter, T. Ressler, B. Bems, C. Büscher, T. Genger, O. Hinrichsen, M. Muhler, and R. Schlögl, Catal. Lett. 71, 37 (2001).

${ }^{52}$ S. Sakong and A. Groß, Surf. Sci. 525, 107 (2003).

${ }^{53}$ J. Wellendorff, K. T. Lundgaard, A. Møgelhøj, V. Petzold, D. D. Landis, J. K. Nørskov, T. Bligaard, and K. W. Jacobsen, Phys. Rev. B 85, 235149 (2012).

${ }^{54}$ P. E. Blöchl, Phys. Rev. B 50, 17953 (1994).

${ }^{55}$ J. Enkovaara, C. Rostgaard, J. J. Mortensen, J. Chen, M. Dułak, L. Ferrighi, J. Gavnholt, C. Glinsvad, V. Haikola, H. A. Hansen, H. H. Kristoffersen, M. Kuisma, A. H. Larsen, L. Lehtovaara, M. Ljungberg, O. Lopez-Acevedo, P. G. Moses, J. Ojanen, T. Olsen, V. Petzold, N. A. Romero, J. Stausholm-Møller, M. Strange, G. A. Tritsaris, M. Vanin, M. Walter, B. Hammer, H. Häkkinen, G. K. H. Madsen, R. M. Nieminen, J. K. Nørskov, M. Puska, T. T. Rantala, J. Schiøtz, K. S. Thygesen, and K. W. Jacobsen, J. Phys. Cond. Mat. 22, 253202 (2010).

${ }^{56}$ S. L. Dudarev, G. A. Botton, S. Y. Savrasov, C. J. Humphreys, and A. P. Sutton, Phys. Rev. B 57, 1505 (1998).

${ }^{57}$ A. H. Larsen, J. J. Mortensen, J. Blomqvist, I. E. Castelli, R. Christensen, M. Dułak, J. Friis, M. N. Groves, B. Hammer, C. Hargus, E. D. Hermes, P. C. Jennings, P. B. Jensen, J. Kermode, J. R. Kitchin, E. L. Kolsbjerg, J. Kubal, K. Kaasbjerg, S. Lysgaard, J. B. Maronsson, T. Maxson, T. Olsen, L. Pastewka, A. Peterson, C. Rostgaard, J. Schiøtz, O. Schütt, M. Strange, K. S. Thygesen, T. Vegge, L. Vilhelmsen, M. Walter, Z. Zeng, and K. W. Jacobsen, J. Phys. Condens. Mat. 29, 273002 (2017). 
${ }^{58}$ R. F. W. Bader, Atoms in Molecules: A Quantum Theory, edited by R. F. W. Bader, International series of monographs on chemistry (Oxford University Press, Oxford, 1990).

${ }^{59}$ W. Tang, E. Sanville, and G. Henkelman, J. Phys. Condens. Matter 21, 084204 (2009).

${ }^{60}$ B. Hammer and J. K. Nørskov, Surf. Sci. 343, 211 (1995).

${ }^{61}$ P. L. Hansen, J. B. Wagner, S. Helveg, J. R. Rostrup-Nielsen, B. S. Clausen, and H. Topsøe, Science 295, 2053 (2002).

${ }^{62}$ S. Kouva, J. Andersin, K. Honkala, J. Lehtonen, L. Lefferts, and J. Kanervo, Phys. Chem. Chem. Phys. 16, 20650 (2014).

${ }^{63}$ A. S. Bazhenov and K. Honkala, Top. Catal. 60, 382 (2017).

${ }^{64}$ J. R. Kitchin, J. K. Nørskov, M. A. Barteau, and J. G. Chen, Phys. Rev. Lett. 93, 156801 (2004). 